\title{
Partial Vaginal Agenesis with Transverse Vaginal Septum
}

\author{
${ }^{1}$ Lakshmidevi Muralidhar, ${ }^{2}$ Shreedhar Venkatesh, ${ }^{3}$ Pramila Pandey
}

\begin{abstract}
Partial vaginal agenesis with transverse vaginal septum is rare malformation of female genital system. The reported incidence of vaginal atresia is 1:4000 to 5000 live female birth. The incidence of septum in upper one-third is $46 \%$, middle $35 \%$, lower $19 \%$. Transverse vaginal septum occurs due to defect in vertical fusion of mullerian ducts during embryogenesis. Vaginal atresia occurs due to failure of canalization of sinovaginal bulbs.

We are presenting such a rare case of partial vaginal agenesis with transverse vaginal septum.

The aim of this presentation is to make the consideration of transverse vaginal septum and vaginal atresia in young girls with cryptomenorrhea and to emphasize on is meticulous evaluation and diagnosis with counselling of a minor along with parents of future reproductive outcome along with surgical difficulties anticipation and difficulties post vangioplasty.
\end{abstract}

Keywords: Partial vaginal agenesis, Transverse vaginal septum, Vaginal atresia.

How to cite this article: Muralidhar L, Venkatesh S, Pandey P. Partial Vaginal Agenesis with Transverse Vaginal Septum. Int J Infertil Fetal Med 2014;5(3):110-112.

Source of support: Nil

Conflict of interest: None

Date of Received: 28-11-14

Date of Acceptance: 02-12-14

Date of Publication: September 2014

\section{INTRODUCTION}

Partial vaginal agenesis with transverse vaginal septum is rare malformation of female genital system. The reported incidence of vaginal atresia is 1:4000 to 5000 live female birth. ${ }^{1,2}$ The incidence of septum in upper onethird is $46 \%$, middle $35 \%$, lower $19 \%$. Transverse vaginal septum occurs due defect in vertical fusion of Mullerian ducts during embryogenesis. Vaginal atresia occurs due to failure of canalization of sinovaginal bulbs.

We are presenting such a rare case of partial vaginal agenesis with transverse vaginal septum.

${ }^{1}$ Assistant Professor, ${ }^{2}$ Professor and Head, ${ }^{3}$ Professor

${ }^{1-3}$ Department of Obstetrics and Gynecology, Vydehi Institute of Medical Sciences and Research Centre, Bengaluru Karnataka, India

Corresponding Author: Lakshmidevi Muralidhar, Assistant Professor, Department of Obstetrics and Gynecology, Vydehi Institute of Medical Sciences and Research Centre, Bengaluru Karnataka, India, Phone: 9886602627, e-mail: dr_lakshmi_ m1982@yahoo.co.in
The aim of this presentation is to make the consideration of transverse vaginal septum and vaginal atresia in young girls with cryptomenorrhea and to emphasize on the meticulous evaluation and diagnosis with counselling of a minor along with parents of future reproductive outcome along with surgical difficulties anticipation and difficulties post vangioplasty.

\section{CASE REPORT}

A patient aged 17 years presents with complaints of cyclical pain abdomen. Pain used to be present once in a month cyclically. No family history of similar complaints. Patient had well developed secondary sexual characters. Height was $146 \mathrm{~cm}$ and no features of Turners syndrome were present and breast development was tanners stage 4 , pubic hair and axillary hair were present, external genitalia was normal. Hymenal opening was not seen and dimple was present in hymenal area. On abdominal examination, a suprapubic bulge was present and it was tender.

Her hormonal analysis was within normal limits, echocardiography (ECHO) normal, X-ray spine normal. Ultrasonography report showed uterus $123 \times 41 \times 74 \mathrm{~mm}$, evidence of hetero-echoic collection in the cervix and the uterine cavity. Collection of around $300 \mathrm{ml}$ in the vagina. Thick septum in lower part of vagina. Lower $1 / 3$ part of vagina was not made out. No renal anomalies were found in the ultrasound (Fig. 1). Magnetic resonance imaging (MRI) was not done as patient was not affordable. Karyotyping was $46 \mathrm{XX}$.

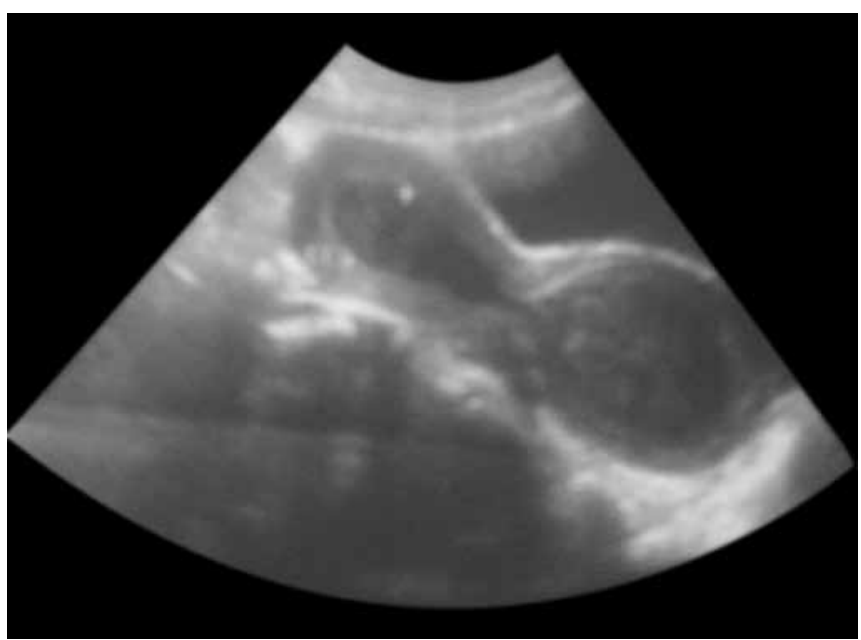

Fig. 1: Ultrasound picture of partial agenesis of vagina and distended upper vagina and uterus with collection 
Clinical diagnosis of partial vaginal agenesis with transverse vaginal septum was made. Patient and attendees were counselled regarding necessasity of surgery, reproductive outcome and coital functions and need of further follow-ups. Case discussed with surgeon and surgical gastroenterologist. In collaboration with them, patient was planned for reconstruction of vagina and incision of septum and drainage of hematocolpos and hematometra. A space was created between bladder and rectum, and space was made till the level of septum (Fig. 2). The septum was incised under ultrasound guidance and approximately $500 \mathrm{ml}$ of collected blood, was drained. As the septum was distended with blood, it was stretched and there was sufficient tissue and septal edges were pulled through and posterior wall was sutured to introitus and anteriorly pulled out and stitched at the level of vaginal introitus (Fig. 3). Intracervical Foleys inserted for the drainage of hematometra and mold was inserted into the vagina. Postoperatively mold was changed everyday. Postoperatively on day 10 , a small speculum was easily inserted and the patient was advised on need of dilatation with mold repeatedly and discharged (Fig. 4). She had menstrual flow for 4 days in next cycle and ultrasound done after menstrual cycle showed patent tract and no collection in vagina and uterus.

\section{DISCUSSION}

Development of female genital tract is a complex process; it is dependent on the events involving cellular differentiation, migration, fusion, canalization. Between the sixth and eighth weeks of fetal development, the caudal aspects of the bilateral Mullerian ducts fuse at the midline. A single midline tubular structure forms as a consequence of cell proliferation (i.e. uterovaginal canal). This midline structure extends to the Mullerian tubercles, where it encounters the urogenital sinus. Bilateral

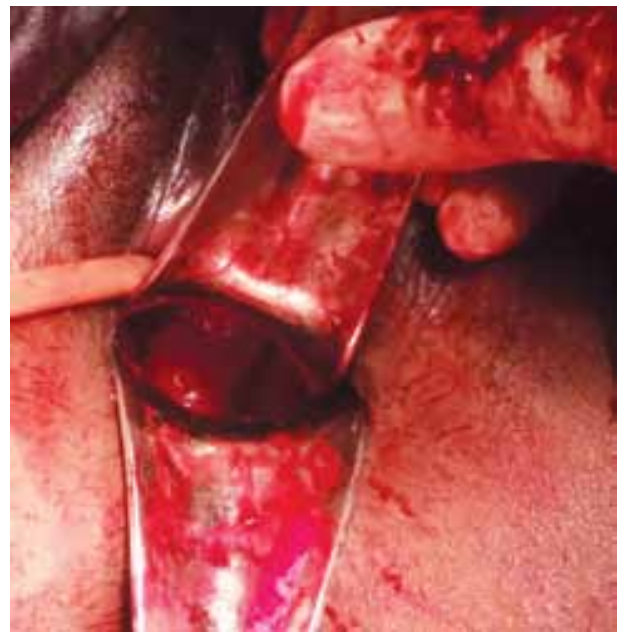

Fig. 2: The creation of space between bladder, rectum and septum endodermal invaginations (i.e. sinovaginal bulbs) form as the Mullerian tubercles regress. Canalization of the uterovaginal canal is believed to occur from the caudal to the cephalic aspect, with an epithelial lining derived from the urogenital sinus. Failures at the vaginal plate level explain transverse vaginal septum and its variant.

Partial vaginal atresia and transverse vaginal septum occur due to defect in above process. ${ }^{3}$ Usual age group of presentation of such anomalies is 19 to 38 years in a girl with well developed secondary sexual character. Transverse vaginal septum follows an autosomal recessive mode of inheritance. ${ }^{4}$ It is associated with genitourinary, gastrointestinal, musculoskeletal and cardiac anomalies. Genitourinary and gastrointestinal anomalies include imperforate anus, malformation of gut, ectopic ureter with hypoplastic kidney, hydronephrosis, musculoskeletal include malformation of lumbar spine and sacral hypoplasia. Cardiac anomalies include coarctation of aorta and ASD. ${ }^{4}$

Usually, they present during adolescent age group with cyclical pain abdomen, suprapubic bulging, very

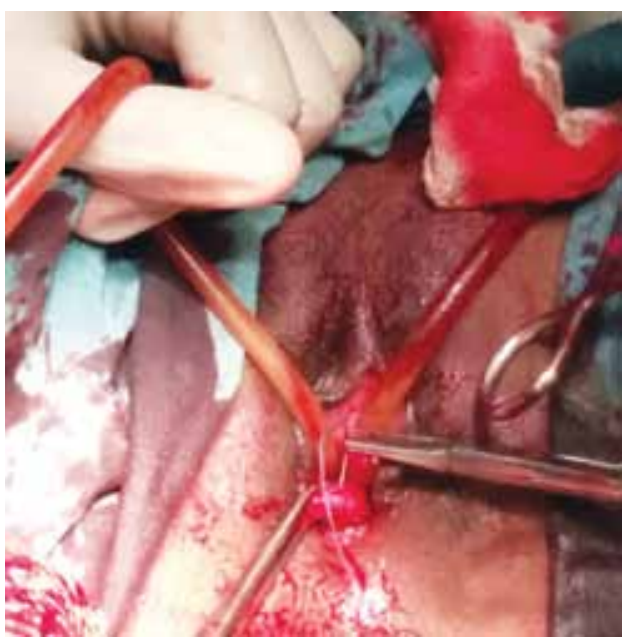

Fig. 3: The suturing of the edges of the septum to the introitus

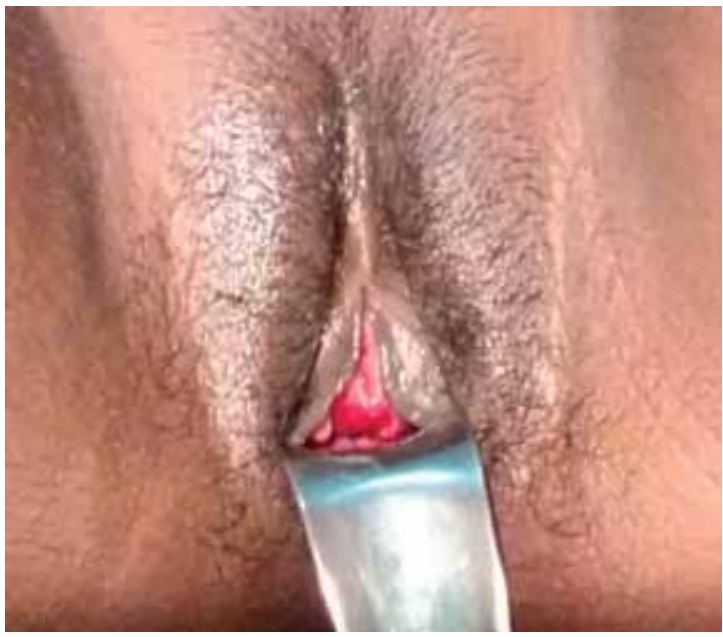

Fig. 4: Postoperative reconstructed vagina 
rarely urinary retention, outflow incontinence, hydronephrosis. ${ }^{5}$ If septum is perforated without vaginal atresia, they may be asymptomatic or with or without dysmenorrhea, infertility, menstrual irregularities, dyspareunia, soft-tissue dystocia. Very rarely if may present at neonatal period with mass per abdomen and pain abdomen. The main treatment modality is surgical. Outcome needs to be considered in such cases is relief of symptoms and sexual function and pregnancy.

Imaging plays an indispensible role in diagnosis of these anomalies. Transverse vaginal septum is pink, thick and does not allow transillumination on clinical examination. On ultrasonography, hourglass distension of upper segment uterus and vagina is made out and sometimes even hematosalphinx can be made out. Magnetic resonance imaging is definitive method. ${ }^{6}$

In our case, we have created the space between the bladder and rectum, septum was incised, and both edges are pulled down and sutured to introitus. Patients own tissue was used so that chances of graft were avoided. Further need of dilatation was emphasized. Early marriage and child bearing was advised to the parents, as they were hematometra and hematosalphinx and chances of endometriosis was explained. Reproductive outcome depends on location of septum retrograde spillage leading to hematometra, hematosalpinx and endometriosis. Coital function depends on the length of vagina reconstructed. Complications of vaginoplasty include injury to the bowel, bladder, infection, blood loss, fistula formation, restenosis, sexual problems and problems with lubrication.

In our study, we want to emphasize that as much as possible we should not resect the septum, rather we should use it for the reconstruction of vagina. Advantages of using the stretched septum for the reconstruction of vagina are since it is an epithelized tract chances of restenosis are very less and graft will take up very nicely and no use of external tissue so there is less chances of infection.

\section{REFERENCES}

1. Mansour O, Morsi H. Management of partial vaginal atresia in infancy: early experience. Annals of Pediatric Surgery 2006 July-Oct;3(2):174-179.

2. Gupta P, Gupta S, Jindal S, Chopra K, Sinha M, Arora A. Cervical dysgenesis with transverse vaginal septum with imperforate hymen in an 11-year-old girl presenting with acute abdomen. J Nepal Med Assoc 2013;52(189):281-284.

3. Jouda MA, Obaideen AM, Zayed M, Hamdy H. Transvaginal excision of transverse vaginal septum in children. JClin Case Rep 2007;3(9). DOI: 10.4172/2165-7920.1000302.

4. Petra M, Polasek, Erickson LD, Stanhop CR. Transverse vaginal septum associated with tubal atresia. Mayo Clio Proc 1995 Oct;1 70:965-968.

5. Khalid E, Jalil S, Anwar T, Nausheen S. Congenital female lower genital tract abnormalities: two years experience in a tertiary care hospital. Pak J Surg 2011;27(1):44-49.

6. Rajanna DK, Chowdareddy N, Kumar JA, Srinivas NS. Transverse vaginal septum - a rare cause of primary amenorrhea: case report. Sch J App Med Sci 2014;2(2C):762-765. 